\title{
Glucose, glutamine and inorganic phosphate in early development of the pig embryo in vitro
}

\author{
R. M. Petters, B. H. Johnson*, M. L. Reed and A. E. Archibong $\dagger$ \\ Reproductive Physiology Research Laboratory, Department of Animal Science, \\ North Carolina State University, Raleigh, NC 27695-7621, USA
}

\begin{abstract}
Summary. Pig embryos at the 1- or 2-cell stage (before the 'block' to development in vitro) were cultured in 8 different media derived from Krebs'-Ringer-bicarbonate medium. A $2 \times 2 \times 2$ factorial arrangement was used for the treatments, with glucose, glutamine and phosphate being the major effects tested. Embryos were obtained from sows approximately $44-48 \mathrm{~h}$ after the observation of oestrus, with the majority being at the 1-cell stage. Embryos from each female were randomly assigned to each treatment. After in-vitro culture, all embryos were scored for the stage of development attained and stained to determine final cell number. Significant effects were evident due to female, glucose, glutamine, a phosphate $\times$ glucose interaction and a glutamine $\times$ glucose interaction. None of the media components tested was inhibitory to embryo development. The greatest development (45-60\% morula or blastocyst) was achieved with glucose and glutamine (both alone and in combination) in the media, demonstrating that an amino acid can serve as the sole energy source for complete preimplantation embryonic development in vitro.
\end{abstract}

Keywords: embryo; pig; in vitro culture; glutamine; glucose; phosphate

\section{Introduction}

Maintaining embryo viability during in-vitro culture is a key to the application of such biotechnologies as embryo splitting, nuclear transplantation and gene transfer by DNA microinjection or retroviral infection. Embryos from most species exhibit less than optimal development in vitro and may 'block' during development at specific cell stages (Bavister, 1987). Because embryos from these animals develop in vivo, the culture medium or environmental conditions used for in-vitro culture must be inferior for supporting normal development.

Pig embryos can develop from the zygote to the blastocyst stage in vitro, but the proportion of embryos obtained before the 4-cell stage that develop to the blastocyst is low (Davis, 1985). This block to development can be overcome in vitro by co-culturing pig embryos with oviducal epithelial cells (White et al., 1989), culturing embryos in medium supplemented with pig oviducal fluid (Archibong et al., 1989) or placing the embryos in mouse oviducts maintained in organ culture (Krisher et al., 1989a, b). While these methods are simple and repeatable, improvement of the defined culture environment remains critical.

Schini \& Bavister (1988) have shown that phosphate and glucose are responsible for the 2-cell block in the hamster. An inhibitory effect for glucose has also been reported for the mouse (Chatot et al., 1989) and the hamster (Seshagiri \& Bavister, 1989a, b). These studies have also demonstrated that amino acids can serve as sole energy sources for development of hamster embryos from the

\footnotetext{
*Present address: University Agricultural Experiment Station, University of Maryland, 1118 Symons Hall, College Park, MD 20742, USA.

†Present address: Oregon Regional Primate Research Center, 505 N.W. 185th Ave., Beaverton, OR 97006, USA.
} 
8-cell to blastocyst stage and that glutamine plays an important role in early development of mouse and hamster embryos in vitro. Davis \& Day (1978) reported that deletion of glucose from culture medium still permitted development of pig embryos from the 4-cell to the blastocyst stage in vitro. In the present study, we have examined the effects of glucose, glutamine and phosphate on the development of pig embryos.

\section{Materials and Methods}

Eight media were formulated by modifying Krebs'-Ringer-bicarbonate medium (Davis \& Day, 1978) (Table 1). The calculated osmolarity of each medium was adjusted to $305-306$ mosmol by adjusting the $\mathrm{NaCl}$ concentration $(114.73$ to $119 \cdot 20 \mathrm{~mm})$. All medium preparations were tested with an osmometer for uniformity as a quality control measure. Media were stored in sterile glass containers at $4^{\circ} \mathrm{C}$ and used within $7-10$ days of preparation. These media were used in a $2 \times 2 \times 2$ factorial arrangement to test the effects of glucose $(5.5 \mathrm{~mm}$ or $0 \mathrm{mM})$, phosphate $\left(\mathrm{KH}_{2} \mathrm{PO}_{4}\right.$, $1.19 \mathrm{~mm}$ or $0 \mathrm{mM}$ ) and glutamine (1 $\mathrm{mM}$ or $0 \mathrm{mM}$ ) on 1-and 2-cell embryos (before the block).

Table 1. Complete culture media used for the culture of early stage pig embryos

\begin{tabular}{lrc}
\hline Ingredient & \multicolumn{1}{c}{$\mathrm{mM}$} & $\mathrm{g} / 1$ \\
\hline $\mathrm{NaCl}$ & $114 \cdot 73$ & $6 \cdot 705$ \\
$\mathrm{KCL}$ & $4 \cdot 78$ & $0 \cdot 356$ \\
$\mathrm{CaCl}$ & $1 \cdot 70$ & $0 \cdot 189$ \\
$\mathrm{KH}_{2} \mathrm{PO}_{4}{ }^{*}$ & $1 \cdot 19$ & $0 \cdot 162$ \\
$\mathrm{MgSO}_{4} \cdot 7 \mathrm{H}_{2} \mathrm{O}$ & $1 \cdot 19$ & $0 \cdot 294$ \\
$\mathrm{NaHCO}_{3}$ & 25.07 & $2 \cdot 106$ \\
Glucose $^{*}$ & $5 \cdot 55$ & $1 \cdot 000$ \\
Glutamine $^{*}$ & $1 \cdot 00$ & $0 \cdot 146$ \\
Bovine serum albumin & & $4 \cdot 000$ \\
(Fraction V) & & \\
Penicillin/streptomycin & \\
(10000 Units/ml and 10 mg/ml)-10 ml/1 \\
Phenol red (1\%)-1 ml/1
\end{tabular}

*Treatment media were compounded by including or not including these ingredients.

Crossbred production sows (Landrace, Yorkshire and Chester White triple crosses) used in the present study were checked twice daily for oestrus with intact Duroc boars. Sows were mated at the time of detected oestrus (Day 0 of gestation) and $24 \mathrm{~h}$ later. Embryos from mated sows were surgically collected from each oviduct according to the method of Vincent et al. (1964) $44-48 \mathrm{~h}$ after the onset of oestrus. One- or 2-cell embryos were washed three times in culture medium lacking glucose, phosphate and glutamine and assessed for viability by visual inspection with the light microscope: 1-cell ova with visible polar bodies and/or spermatozoa embedded in the zona pellucida and 2-cell embryos with blastomeres of equal size were used.

Each sow was used as a random block, contributing an equal number of viable embryos to each treatment. Sows were not used when fewer than 8 viable embryos were recovered. One sow contributed 16 embryos. Consequently, embryos from 19 females (160 embryos, 1-or 2 -cell stages) were cultured in the 8 media, 20 embryos/medium. The embryos were cultured individually in $1 \mathrm{ml}$ medium in Corning Cell Well $\mathrm{m}$ plates (No. 25820, Corning Glass Works, Corning, NY, USA) in a sealed, humidified glass desiccator gassed with $5 \% \mathrm{O}_{2}-5 \% \mathrm{CO}_{2}-90 \% \mathrm{~N}_{2}$ and maintained at $37^{\circ} \mathrm{C}$ in a tissue culture incubator. The length of culture in vitro depended on the stage of development of the embryos at recovery ( 1 cell $=6$ days; 2 cell $=5$ days). At the end of the culture period, embryos were scored for morphological stage of development by light microscopy and for final cell number after staining and counting of nuclei using the technique of Pursel et al. (1985).

Each embryo was given a numerical score based on its morphological stage of development as follows: dead or degenerate $=1$; cleavage $=2$; morula $=3$; blastocyst $=4$. These scores were used to calculate the morphological stage of development attained for embryos in each treatment. Statistical analyses of the data were accomplished with the General Linear Model of the Statistical Analysis System (SAS, Cary, NC, USA). The complete model included the main effects (female, glucose, glutamine, phosphate), interactions (between glucose, glutamine and phosphate) with initial cell number as a covariate. Comparisons between least square means were made by $t$ tests. 


\section{Results}

Embryo development for each treatment medium is shown in Table 2. Generally, all treatments with glucose or glutamine or both in the medium were similar. One exception was the treatment with phosphate and glucose (lacking glutamine) which is the usual culture medium. In this case, development appeared to be reduced, being significantly different from a number of the other media. Medium lacking any exogenous energy source (i.e. lacking both glucose and glutamine) did not support development much beyond the 4-cell stage, although the medium with phosphate alone did support some degree of development past cleavage ( $20 \%$ morula and blastocyst).

Table 2. Summary of the effects of different media with glucose $( \pm)$, glutamine $( \pm)$ and phosphate $( \pm)$ for culture of 1 and 2-cell pig embryos

\begin{tabular}{|c|c|c|c|c|c|c|c|c|c|c|}
\hline \multicolumn{3}{|c|}{ Medium } & \multirow[b]{2}{*}{$\begin{array}{l}\text { No. of } \\
\text { embryos }\end{array}$} & \multicolumn{5}{|c|}{ Stage of development (cell no.) } & \multicolumn{2}{|c|}{ LS mean } \\
\hline $\mathrm{PO}$ & G & Gln & & Deg & $\mathrm{Cl}$ & $\mathbf{M}$ & B & $\% \mathrm{M}+\mathrm{B}$ & $\begin{array}{c}\text { Stage of } \\
\text { development* }\end{array}$ & $\begin{array}{c}\text { Final cell } \\
\text { no. } \dagger\end{array}$ \\
\hline+ & + & + & 20 & $1(2 \cdot 0)$ & $9(8 \cdot 4)$ & $4(22 \cdot 5)$ & $6(62 \cdot 5)$ & 50 & 2.69 & $25 \cdot 6$ \\
\hline- & + & + & 20 & 0 & $8(6.6)$ & $3(23 \cdot 3)$ & $9(53.8)$ & 60 & 2.99 & $28 \cdot 8$ \\
\hline+ & + & - & 20 & $1(1 \cdot 0)$ & $10(7 \cdot 1)$ & $7(18 \cdot 6)$ & $2(47.5)$ & 45 & $2 \cdot 44$ & $13 \cdot 3$ \\
\hline- & + & - & 20 & 0 & $8(6.9)$ & $6(21 \cdot 3)$ & $6(56 \cdot 0)$ & 60 & 2.84 & $24 \cdot 4$ \\
\hline+ & - & + & 20 & 0 & $9(4 \cdot 0)$ & $5(20 \cdot 6)$ & $6(55 \cdot 2)$ & 55 & 2.79 & $22 \cdot 0$ \\
\hline- & - & + & 20 & $1(1.0)$ & $9(4 \cdot 8)$ & $6(24 \cdot 7)$ & $4(59 \cdot 3)$ & 50 & 2.59 & 19.9 \\
\hline+ & - & - & 20 & $3(1 \cdot 3)$ & $13(3.9)$ & $3(29 \cdot 7)$ & $1(47.0)$ & 20 & $2 \cdot 04$ & $7 \cdot 8$ \\
\hline- & - & - & 20 & $8(1.4)$ & $12(4.9)$ & 0 & 0 & 0 & 1.54 & 1.8 \\
\hline
\end{tabular}

$\mathrm{PO}=$ phosphate $\mathrm{G}=$ glucose; $\mathrm{Gln}=$ glutamine; Deg = degenerate; $\mathrm{Cl}=$ cleavage; $\mathrm{M}=$ morula; $\mathrm{B}=$ blastocyst. *s.e. of all means, $0 \cdot 16$.

ts.e. of all means, 3.64-3.66.

Significant effects in the statistical model, based on stage of development, were female, glucose, glutamine, and interactions of phosphate with glucose and glutamine with glucose (Table 3). The stage of embryonic development at the beginning of the culture period (1- or 2-cell) did not influence subsequent development in vitro. The greatest development (45-60\% morulae and blastocysts) was achieved with glucose and/or glutamine (both alone or in combination) in the media (Table 2). The effect of glutamine was independent of the presence of phosphate in the media. The interaction noted for glutamine and glucose indicated that media with glutamine and with or without glucose resulted in equal development, but media without glutamine supported development only when glucose was present. Phosphate and glucose interacted with each other and a greater degree of development occurred in the absence of phosphate when glucose was present.

Analysis based on the number of cell divisions achieved in vitro indicated that significant effects were female, glucose, glutamine and an interaction of phosphate with glucose (Table 3). The greatest numbers of cells were achieved in media containing glucose and glutamine (both alone or in combination). Average cell numbers attained for morulae across all treatments ranged from 19 to 30 cells (nuclei) per embryo, while for blastocysts the averages ranged from 47 to 63 cells (nuclei) per embryo.

Thus, for both stage of development and final cell number data, glucose or glutamine could serve as the sole exogenous energy source. Glucose and glutamine in combination were not better than either energy source alone.

\section{Discussion}

The majority of the in-vitro embryonic development data has been gathered from studies of the mouse embryo. Several early studies were conducted to elucidate the needs of the preimplantation 
Table 3. Analysis of variance of the complete data set for 160 pig embryos cultured in 8 different media with dependent variables of stage of development attained or final cell number

\begin{tabular}{|c|c|c|c|c|c|}
\hline \multirow[b]{2}{*}{ Source } & \multirow[b]{2}{*}{ d.f. } & \multicolumn{2}{|c|}{ Stage of development } & \multicolumn{2}{|c|}{ Final cell no. } \\
\hline & & Mean square & $F$ value & Mean square & F value \\
\hline Female & 18 & $2 \cdot 02$ & $4 \cdot 09^{* * *}$ & $1518 \cdot 58$ & $5.79^{* * *}$ \\
\hline Phosphate (PO) & 1 & 0.00 & 0.00 & $96 \cdot 10$ & $0 \cdot 37$ \\
\hline Glucose $(G)$ & $i$ & 9.08 & $18 \cdot 37^{* * *}$ & $3687 \cdot 35$ & $14 \cdot 05^{* * *}$ \\
\hline Glutamine (Gln) & 1 & $11 \cdot 07$ & $22 \cdot 40^{* * * *}$ & 5436.61 & $20 \cdot 72^{* * *}$ \\
\hline$P O \times G$ & $i$ & 4.90 & $9 \cdot 91^{* *}$ & $1254 \cdot 40$ & $4 \cdot 78^{*}$ \\
\hline $\mathrm{PO} \times \mathrm{G} \ln$ & 1 & $0 \cdot 10$ & $0 \cdot 20$ & 38.03 & $0 \cdot 14$ \\
\hline $\mathrm{G} \times \mathrm{Gln}$ & 1 & $4 \cdot 30$ & $8 \cdot 70^{* *}$ & $457 \cdot 13$ & 1.74 \\
\hline $\mathrm{PO} \times \mathrm{G} \times \mathrm{Gln}$ & 1 & $0 \cdot 40$ & 0.81 & 354.03 & $1 \cdot 35$ \\
\hline Initial cell no. & 1 & 0.85 & 1.72 & $346 \cdot 63$ & $1 \cdot 32$ \\
\hline Error & 133 & 0.49 & & $262 \cdot 42$ & \\
\hline
\end{tabular}

${ }^{*} P<0.05 ;{ }^{* *} P<0.01,{ }^{* * *} P<0.001$.

mouse embryo, in terms of nitrogen and energy requirements, as well as the physico-chemico requirements (for review see: Biggers et al., 1967; Brinster, 1969, 1973; Biggers, 1987). The mouse embryo undergoes temporal changes in cellular respiratory requirements. At the 1- and 2-cell stages pyruvate and lactate can support development while glucose cannot. Additionally, early stage embryos can utilize a portion of the available glucose via the pentose phosphate pathway for the production of reducing compounds and phosphorylated pentose sugars. The activity of this system declines as development proceeds to the blastocyst stage (O'Fallon \& Wright, 1986). During the later stages of development, glucose is utilized preferentially, beginning at the morula and blastocyst stages. One possible reason behind the differential energy substrate requirements may be the lack of a functional glycolytic pathway in the early cleavage stages. A block to glycolysis is suspected due to decreased 6-phosphofructokinase activity. This block is removed with further embryonic development, as indicated by increased enzyme activity (Barbehenn et al., 1974, 1978).

The hamster embryo exhibits several blocks to development before blastocyst formation (Bavister, 1987, 1988). Major deviations in the formulation of culture media for hamster embryos have produced surprising results. The inclusion of phosphate and glucose in hamster embryo culture medium has been found to be strongly inhibitory; removal of these compounds allowed for greater development of 2-cell embryos to the 8-cell/morula stages and greater development of 8-cell embryos to blastocysts (Schini \& Bavister, 1988; Seshagiri \& Bavister, 1989a, b). A requirement for vitamins (inositol, pantothenate, and choline) to promote hatching of hamster embryos in vitro has also been demonstrated (Kane \& Bavister, 1988).

The addition of glutamine and the deletion of glucose from media has also resulted in increased in-vitro development of 1-cell mouse embryos that exhibit a block at the 2-cell stage. Glutamine was found to be important for the transition through the developmental block while glucose was inhibitory. The requirement for glutamine was lost at the 4- to 8-cell transition and glucose became necessary for further embryonic development (Chatot et al., 1989).

In the present study, media containing glucose, as energy source, permitted a greater number of pre-block pig embryos to reach the morula and blastocyst stages compared with media lacking an energy source. The intrepretation of the significance of glucose for pig embryo culture in vitro is beset by the conflicting results reported by Pope (1972) on in-vitro culture of 1-4 cell pig embryos in Brinster's medium for ovum culture- $2+$ glucose. The result of the present study regarding the influence of glucose on the trend of embryonic development is similar to that obtained in the first experiment conducted by Pope (1972). However, the percentage of blastocyst formation observed in this study is higher than that observed by Pope (1972). It is possible that media containing glucose may have provided more energy for embryonic development via the glycolytic pathway papm $_{10 \mathrm{P}}$ 
after two cleavage divisions, compared with media without glucose. According to Flood \& Wiebold (1988) the early pig embryo (1-4-cell stage) uses the pentose phosphate pathway for the metabolism of glucose to a greater extent than glycolysis. However, the utilization of glucose through the glycolytic pathway increases with embryonic development. Because glucose and inorganic phosphate together in culture medium did not cause an increase in percentage of morula and blastocyst formation beyond that observed when glucose alone was present, the inorganic phosphate required for the phosphorylation of glucose for the onset of glycolysis may have been endogenous. The highly significant effect of female (sow) has been noted previously (Krisher et al., 1989a; Archibong et al., 1989) and is either due to genetic differences among sows or effects of surgery on individual sows.

The end product of glycolysis is pyruvate or lactate which have been shown to inhibit pig embryo development (Davis \& Day, 1978). In the in-vitro embryo culture system used in this study, in which one embryo was cultured in $1 \mathrm{ml}$ medium, the amount of pyruvate produced by the embryo probably was not up to the threshold required to inhibit embryonic development. In the oviduct, pyruvate produced as a result of glycolytic activity within the embryo may be taken up by the cells of this organ, thus reducing the likelihood of pyruvate inhibiting embryonic development. Bavister (1988) and Krisher et al. (1989b) have suggested that oviducal cells play a role in the removal of toxic factors in the environment of the early developing embryo.

Glutamine alone or in combination with glucose or inorganic phosphate sustained the development of pig embryos to the morula and blastocyst stages to the same extent as did glucose. Glutamine has been shown to be an energy substrate for a variety of somatic cells in vitro (Eagle et al., 1955; Zielke et al., 1978; Reitzer et al., 1979). In terms of uptake and utilization by mammalian oocytes and embryos, glutamine has been shown to be beneficial for hamster oocytes and embryos, as well as rabbit oocytes in vitro (Gwatkin \& Haidri, 1973; Bavister et al., 1983; Bae \& Foote, 1975; Carney \& Bavister, 1987). Mouse embryos can also utilize glutamine as an energy source (Brinster, 1971, 1973; Chatot et al., 1989, 1990).

The ability of glutamine to support embryo development in the absence of glucose demonstrates its ability to replace glucose as the carbon source for energy production. These findings are supported by those of Stone et al. (1984) who obtained greater development of 4-8-cell pig embryos in vitro in minimal essential medium (MEM) containing glutamine, over that of Krebs'-Ringer bicarbonate medium supplemented with glucose. However, Meyen et al. (1989) found no beneficial effect of glutamine on development of morulae and blastocysts. According to these investigators, an inhibitory effect was observed with the inclusion of the amino acid and vitamin complexes present in MEM. These observations, in light of the present findings, suggest that a difference may exist in the sensitivity of the pig embryo to the MEM components over time, specific amino acids or vitamins, and that glutamine appears to exert a positive effect, particularly at the early stages of development. However, Rosenkrans et al. (1989) concluded that glutamine improved development of pig blastocysts in vitro. All media in the present study contained bovine serum albumin which may contain substrates for energy production as contaminants. However, medium lacking glutamine and glucose did not support much embryo development. The final cell numbers attained by pre-block pig embryos cultured in vitro in the present study are similar to those observed by Krisher et al. (1989b) with pig zygotes in mouse oviducts in organ culture, and in-vitro culture of pig 4-cell (Davis \& Day, 1978; Niemann et al., 1983), and morulae and blastocysts (Meyen et al., 1989) stages.

The presence of glucose in the present study was found to be necessary (in the absence of glutamine) for in-vitro development to proceed, and was not inhibitory to development, as it is for mouse and hamster embryos (see above). The presence of phosphate in the medium had no overt beneficial or negative effects on development, but an interaction between phosphate and glucose was observed. This interaction indicated a negative effect of phosphate in those media in which glucose was present, and this may be analogous to the inhibitory effects seen with hamster embryos (Schini \& Bavister, 1988; Seshagiri \& Bavister, 1989a, b). 
In conclusion, this study demonstrated that a greater proportion of 1- and 2-cell pig embryos developed in the presence of glucose and glutamine (both alone and in combination) than when both were absent, as measured by stage of embryonic development and the number of cell divisions achieved during the culture period. No inhibitory effects were observed for glucose or glutamine. Development of 1- or 2-cell embryos through the 4-cell in-vitro development block to morula and blastocyst stages was demonstrated in treatments in which glutamine was the sole exogenous energy source.

Paper No. 12243 of the Journal Series of the North Carolina Agricultural Research Service, Raleigh 27695-7601. The use of trade names in this publication does not imply endorsement by the North Carolina Agricultural Research Service of the products named nor criticism of similar ones not mentioned. This work was done as part of a National Cooperative Program on Non-Human In Vitro Fertilization and Preimplantation Development and was funded by the National Institute of Child Health and Human Development, NIH, through cooperative agreement HD 21937. We thank R. J. Tasca, B. D. Bavister, J. D. Biggers and C. A. Ziomek for discussion and B. Collins and B. Houston for technical assistance.

\section{References}

Archibong, A.E., Petters, R.M. \& Johnson, B.H. (1989) Development of porcine embryos from one- and twocell stages to blastocysts in culture medium supplemented with porcine oviductal fluid. Biol. Reprod. 41, 1076-1083.

Bae, I-H. \& Foote, R.H. (1975) Carbohydrate and amino acid requirements and ammonia production of rabbit follicular oocytes in vitro. Expl Cell Res. 91, 113-118.

Barbehenn, E.K., Wales, R.G. \& Lowry, O.H. (1974) The explanation for the blockade of glycolysis in early mouse embryos. Proc. natn. Acad. Sci. USA 71, $1056-1060$.

Barbehenn, E.K., Wales, R.G. \& Lowry, O.H. (1978) Measurement of metabolites in single preimplantation embryos; a new means to study metabolic control in early embryos. J. Embryol. exp. Morph. 43, $29-46$.

Bavister, B.D. (1987) Studies on the developmental blocks in cultured hamster embryos. In The Mammalian Preimplantation Embryo. Regulation of Growth and Differentiation in Vitro, pp. 219-249. Ed. B. D. Bavister. Plenum Press, New York.

Bavister, B.D. (1988) Role of oviductal secretions in embryonic growth in vivo and in vitro. Theriogenology 29, 143-154.

Bavister, B.D., Leibfried, M.L. \& Lieberman, G. (1983) Development of preimplantation embryos of the golden hamster in a defined culture medium. Biol. Reprod. 28, 235-247.

Biggers, J.D. (1987) Pioneering mammalian embryo culture. In The Mammalian Preimplantation Embryo. Regulation of Growth and Differentiation in Vitro, pp. 1-22. Ed. B. D. Bavister. Plenum Press, New York.

Biggers, J.D., Whittingham, D.G. \& Donahue, R.P. (1967) The pattern of energy metabolism in the mouse oocyte and zygote. Proc. natn. Acad. Sci. USA 58, 560-567.

Brinster, R.L. (1969) Mammalian embryo culture. In The Mammalian Oviduct. Comparative Biology and
Methodology, pp. 419-444. Eds. E. S. E. Hafez \& R. J. Blandau. University of Chicago Press, Chicago.

Brinster, R.L. (197I) Uptake and incorporation of amino acids by the preimplantation mouse embryo. $J$. Reprod. Fert. 27, 329-338.

Brinster, R.L. (1973) Nutrition and metabolism of the ovum, zygote, and blastocyst. In Handbook of Physiology, pp. 165-185. Eds. R. O. Greep, E. D. Astwood \& S. R. Geiger. Waverly Press, Inc., Baltimore.

Carney, E.W. \& Bavister, B.D. (1987) Stimulatory and inhibitory effects of amino acids on the development of hamster eight-cell embryos in vitro. J. In Vitro Fertil. \& Embryo Transfer 4, 162-167.

Chatot, C.L., Ziomek, C.A., Bavister, B.D., Lewis, J.L. \& Torres, I. (1989) An improved culture medium supports development of random-bred 1-cell mouse embryos in vitro. J. Reprod. Fert. 86, 679-688.

Chatot, C.L., Tasca, R.J. \& Ziomek, C.A. (1990) Glutamine uptake and utilization by preimplantation mouse embryos in CZB medium. J. Reprod. Fert. 89, 335-346.

Davis, D.L. (1985) Culture and storage of pig embryos. $J$. Reprod. Fert., Suppl. 33, 115-124.

Davis, D.L. \& Day, B.N. (1978) Cleavage and blastocyst formation by pig eggs in vitro. J. Anim. Sci. 46, 1043-1053.

Eagle, H., Oyama, V.I., Levy, M., Horton, C.L. \& Fleischman, R. (1955) The growth response of mammalian cells in tissue culture to L-glutamine and L-glutamic acid. J. biol. Chem. 218, 607-616.

Flood, M.R. \& Wiebold, J.L. (1988) Glucose metabolism by primplantation pig embryos. J. Reprod. Fert. 84, $7-12$.

Gwatkin, R.B.L. \& Haidri, A.A. (1973) Requirements for the maturation of hamster oocytes in vitro. Expl Cell Res. 76, 1-7.

Kane, M.T. \& Bavister, B.D. (1988) Vitamin requirements for development of eight-cell hamster embryos to hatching blastocysts in vitro. Biol. Reprod. 39, l137-1143. 
Krisher, R.L., Petters, R.M., Johnson, B.H., Bavister, B.D. \& Archibong, A.E. (1989a) Development of porcine embryos from the one-cell stage to blastocyst in mouse oviducts maintained in organ culture. $J$. exp. Zool. 249, 235-239.

Krisher, R.L., Petters, R.M. \& Johnson, B.H. (1989b) Effect of oviductal condition on the development of one-cell porcine embryos in mouse or rat oviducts maintained in organ culture. Theriogenology 32, 885-892.

Meyen, B.A., Rosenkrans, C.F., Jr \& Davis, D.L. (1989) Development of pig blastocysts in vitro is altered by serum, bovine serum albumin and amino acids and vitamins. Theriogenology 31, 463-471.

Niemann, H., Illera, M.J. \& Dzuik, P.J. (1983) Developmental capacity, size and number of nuclei in pig embryos cultured in vitro. Anim. Reprod. Sci. 5, $311-321$.

O'Fallon, J.V. \& Wright, R.W., Jr (1986) Quantitative determination of the pentose phosphate pathway in preimplantation mouse embryos. Biol. Reprod. 34, 58-64.

Pope, C.E. (1972) In vitro culture of preimplantation pig embryos. Ph.D. thesis. University of MissouriColumbia.

Pursel, V.G., Wall, R.J., Rexroad, Jr, C.E., Hammer, R.E. \& Brinster, R.L. (1985) A rapid whole mount staining procedure for nuclei of mammalian embryos. Theriogenology 24, 687-691.

Reitzer, L.J., Wice, B.M. \& Kennell, D. (1979) Evidence that glutamine, not sugar, is the major energy source for cultured HeLa cells. J. biol. Chem. 254, 2669-2676.
Rosenkrans, C.F., Jr, Davis, D.L. \& Milliken, G. (1989) Pig blastocyst development in vitro is affected by amino acids. J. Anim. Sci. 67, 1503-1508.

Schini, S.A. \& Bavister, B.D. (1988) Two-cell block to development of cultured hamster embryos is caused by phosphate and glucose. Biol. Reprod. 39, 1183-1192.

Seshagiri, P.B. \& Bavister, B.D. (1989a) Phosphate is required for inhibition by glucose of development of hamster 8-cell embryos in vitro. Biol. Reprod. 40, $607-614$.

Seshagiri, P.B. \& Bavister, B.D. (1989b) Glucose inhibits development of hamster 8-cell embryos in vitro. Biol. Reprod. 40, 599-606.

Stone, B.A., Quinn, P. \& Seamark, R.F. (1984) Energy and protein sources for development of pig embryos cultured beyond hatching in vitro. Anim. Reprod. Sci. 7, 405-412.

Vincent, C.K., Robison, O.W. \& Ulberg, L.C. (1964) A technique for reciprocal embryo transfer in swine. $J$. Anim. Sci. 23, 1084-1088.

White, K.L., Hehnke, K., Rickords, L.F., Southern, L.L., Thompson, D.L., Jr \& Wood, T.C. (1989) Early embryonic development in vitro by coculture with oviductal epithelial cells in pigs. Biol. Reprod. 41, 425-430.

Zielke, H.R., Ozand, P.T., Tildon, J.T., Sevdalian, D.A. \& Cornblath, M. (1978) Reciprocal regulation of glucose and glutamine utilization by cultured human diploid fibroblasts. J. Cell. Physiol. 95, 41-48. 